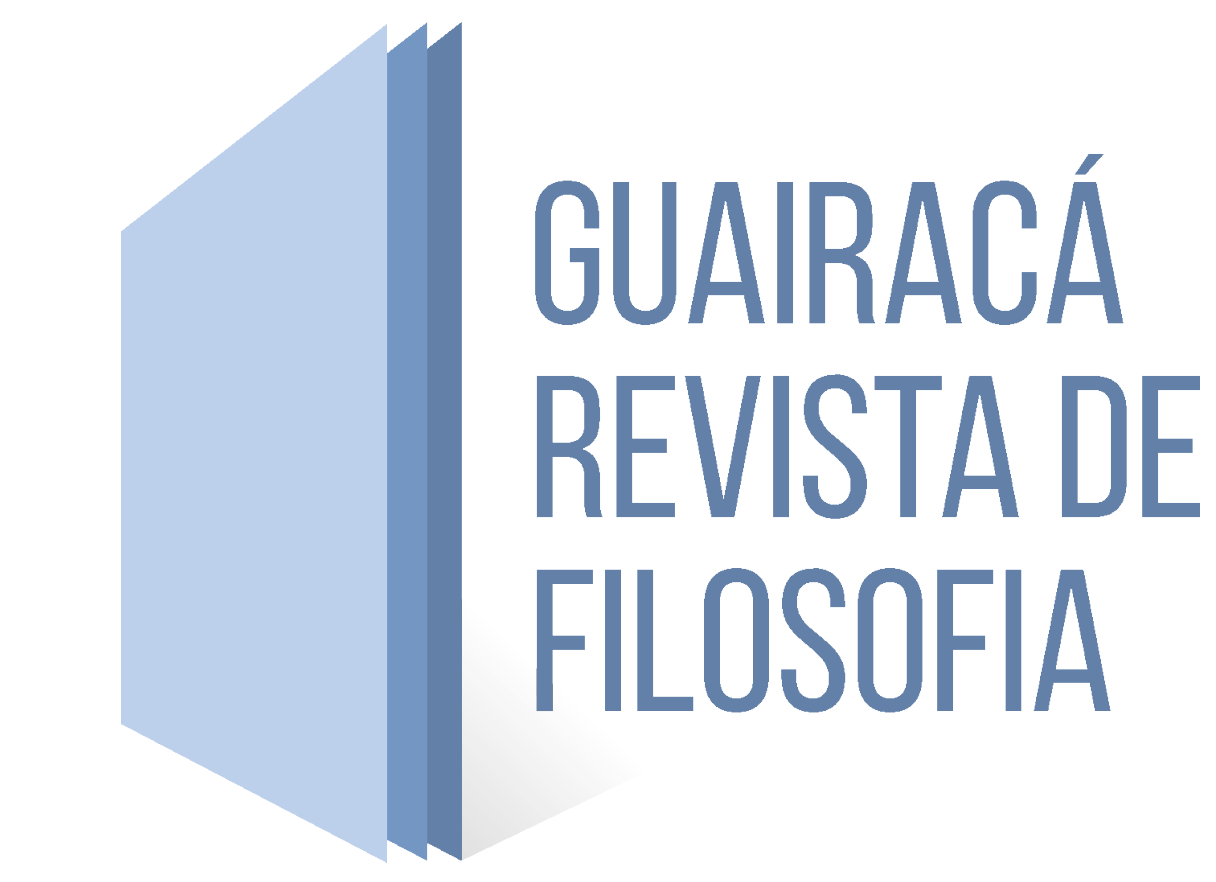

\title{
TELEOLOGIA E NECESSIDADE NATURAL EM ARISTÓTELES
}

Resumo: Neste artigo, procurarei examinar por que, em Aristóteles, as composições orgânico-animadas, no mais das vezes, ocorrem segundo certa finalidade. $\mathrm{Na}$ medida em que a forma atua como fator causal de caráter teleológico, ela regula as propriedades e os movimentos necessários da matéria elementar, de modo a concatená-los de acordo com certo arranjo composicional. Neste sentido, a necessidade absoluta procedente das propriedades essenciais dos elementos, os quais servem de substrato material às partes do ser vivo na compleição orgânica, se dá sob hipótese, ou seja, sob a intervenção da forma do animal. Tais propriedades são apropriadas pelo organismo, ajustando-as em vista das atividades vitais, de modo a promover a emergência de novas propriedades que os elementos, por si mesmos, através de uma interação espontânea, seriam incapazes de adquirir. Deste modo, pretendo mostrar que a necessidade hipotética da teleologia ou a necessidade natural, no processo de constituição orgânica, incorpora a necessidade absoluta da matéria elementar, adequando-a as exigências da vida.

Palavras-chave: Teleologia. Necessidade Natural. Hilemorfismo. Organismos Vivos. Aristóteles.

1. Doutor em Filosofia pela USP. E-mail: romaodc@gmail.com. 


\section{NATURAL TELEOLOGY ANDNECESSTTY IN ARISTOTLE}

Abstract: In this paper, I'll try to examine why, in Aristotle, organic-animated compositions for the most part occur according to a finality. To the extent that form acts as a causal factor of teleological character, it regulates the properties and necessary movements of matter, so that to concatenate them according to a certain compositional arrangement. In this sense, the absolute necessity, coming from the essential properties of the elements, which serve as a material substrate to the parts of the living being in the organic complexion, takes place under hypothesis, that is, under the intervention of the animal's form. Such properties are appropriated by the organism, adjusting them in view of vital activities, in order to promote the emergence of new properties which the elements, by themselves, through spontaneous interaction, would be unable to acquire. In this way, I intend to show that the hypothetical necessity of teleology or natural necessity, in the process of organic constitution, incorporates the absolute necessity of elementary matter, adapting it to the demands of life.

Keywords: Teleology. Natural Necessity. Hylemorphism. Living Organisms. Aristotle.

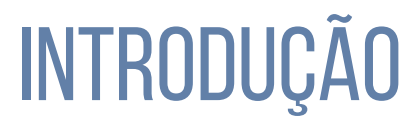

No capítulo 8 do Livro II da Física, Aristóteles questiona se os processos naturais poderiam ocorrer exclusivamente segundo uma necessidade simples, proveniente dos elementos materiais, ou se seria preciso admitir uma causalidade de tipo teleológica, atuando sobre esta necessidade, estritamente material. Com esta problemática em vista, ele estabelece como exemplo uma comparação entre (i) o fenômeno da chuva, na medida em que promove benefícios à agricultura, e (ii) a constituição dos seres vivos, na medida em que suas partes são capazes de promover o bom funcionamento do organismo (Ph.198b16-25).

Uma vez que o fenômeno pluvial é explicado através de movimentos necessários, oriundos, unicamente, da matéria elementar, não se pode afirmar, por exemplo, que o crescimento do trigo advém à chuva como uma decorrência teleológica, pois se "é preciso que se resfrie aquilo que foi levado para cima, e é preciso que aquilo que se resfriou, tendo-se tornado água, volte" (Ph. 198b18-20), não se segue que a boa safra venha a ser um resultado em vista do qual chove. Os processos absolutamente necessários pelos quais se determina o fenômeno pluvial 
independem de uma boa produção agrícola. Do mesmo modo, não é em vista de o trigo perecer na eira que chove, mas simplesmente acontece, por uma relação de concomitância, e não por uma relação de implicação mútua, chover e o trigo perecer (Ph.198b21-22), ou chover e o trigo crescer. A partir destas considerações, coloca-se a questão de saber se o mesmo poderia ocorrer no caso da matéria elementar do vivente, relativamente às partes que permitem ao organismo exercer as suas funções características (BOSTOCK, 2006, p. 50). Neste sentido, Aristóteles irá dizer:

O que impediria que também as partes na natureza se comportassem desse modo - por exemplo, que, por necessidade, os dentes dianteiros se perfaçam agudos, adaptados para dividir, e os molares se perfaçam largos e úteis para aplainar o alimento, uma vez que não teriam vindo a ser em vista disso, mas antes assim teria coincidido? Semelhantemente, também para as demais partes, em todas nas quais se julga encontrar o em vista de algo ${ }^{2}(P h .198 b 23-28)$.

Tal como a relação, até aqui concebida, entre (i) chuva e (ii) boa safra, o que impediria que o mesmo tipo de relação não ocorresse entre (i) as interações necessárias dos materiais elementares e (ii) a formação de partes habilitadas ao desempenho de certas funções orgânicas? Se assim for, a natureza operaria segundo uma combinação aleatória dos movimentos absolutamente necessários da matéria, de modo que resultaria numa mera coincidência, por exemplo, o fato de os dentes dianteiros serem agudos e apropriados para dividir, ou de os molares serem largos e apropriados para aplainar o alimento.

Eventos espontâneos ou casuais são determinados por uma conjunção concomitante de séries causais independentes entre si, as quais não convergem para a produção de qualquer resultado predeterminado. Ora, se os dentes dianteiros ou molares - ou quaisquer que sejam as partes aptas a realizar funções - são determinados exclusivamente por uma interação concomitante de séries causais, através dos movimentos necessários dos elementos materiais, as disposições funcionais dos organismos seriam, portanto, um produto do espontâneo ou do acaso. Aristóteles, no entanto, se posicionará contra esta concepção, que seria defendia por seus adversários, notadamente Empédocles ${ }^{3}$.

\section{TELEOLOGIA NATURAL}

2. De um modo geral, com relação às citações das obras de Aristóteles traduzidas para o português, utilizei a edição "Bekker I", as traduções para o inglês das edições bilíngues da "Loeb Classical Library", as traduções para o espanhol das edições "Gredos", e as traduções para o português de L. Angioni do Livro I das Partes dos Animais. De um modo estrito, com relação às traduções do livro II da Física de Aristóteles, utilizei a tradução de L. Angioni: Física I-II, Campinas, Ed. Unicamp, 2009.

3. Citado em 198b31-32. Demócrito, também, parece ser o alvo de Aristóteles (Gen. An.789b2-8). 
De acordo com a teleologia natural de Aristóteles, pode-se afirmar que os entes naturais não são uma decorrência direta dos movimentos absolutamente necessários da matéria bruta, embora a necessidade proveniente dos elementos não deixe de estar envolvida no processo de constituição dos seres vivos. Os organismos não resultam tão somente da necessidade da matéria, mas do direcionamento teleológico pelo qual as séries causais, procedentes da necessidade dos elementos, naturalmente se submetem. Assim, na perspectiva de Aristóteles, a comparação entre natureza e a conjunção entre o fenômeno pluvial e o bom resultado agrícola deve ser interpretado do seguinte modo: tanto o ente natural, "produto" da natureza, quanto a boa safra, produto da técnica agrícola, são originados através de uma causalidade teleológica, a qual intervém sobre a necessidade da matéria. No primeiro caso, a causalidade teleológica intervém sobre as propriedades dos elementos, reordenandoas de modo a se adequarem aos fatores funcionais requisitados pelos organismos; no segundo, a causalidade teleológica intervém sobre os movimentos que resultam da chuva, reordenando-os de modo a promover uma irrigação eficaz, mediante o preparo da terra, a técnica de plantio etc.

Natureza e técnica, então, compartilham uma mesma racionalidade teleológica. A partir de determinado acabamento, estipulado como princípio, certos eventos apresentam-se como condições sine qua non para a efetividade deste acabamento, ainda que estes eventos existam por si mesmos, sendo regulados por uma necessidade própria. Na natureza, as propriedades dos elementos materiais são reordenadas segundo as exigências requisitadas pelas funções vitais, de modo a constituir o organismo, o qual é caracterizado e definido por ser capaz de, ao menos, nutrir-se e reproduzir-se. Semelhantemente, na técnica, os movimentos decorrentes da chuva, por exemplo, são reordenados conforme a finalidade agrícola, permitindo o crescimento ou a maturação do trigo, de modo a servir de alimento, ou de produção a ser comercializada (ANGIONI, 2009, p. 355). A diferença é que, na natureza, a intervenção da causalidade teleológica sobre a necessidade material se dá de um modo intrínseco a própria natureza, e, na técnica, de um modo extrínseco, artificial.

De um ponto de vista geral, o que Aristóteles pretende mostrar é que a constituição dos entes naturais não pode ser um mero resultado do espontâneo (autómaton), como sustenta Empédocles, pois, caso contrário, não teria como explicar a regularidade com a qual eles se apresentam no mundo:

As coisas naturalmente geradas se geram todas, sempre ou no mais das vezes, de uma determinada maneira, enquanto que as exceções ao que sucede sempre ou no mais das vezes surgem do espontâneo ou do acaso. Qual é, então, a razão pela qual, sempre ou na maioria dos casos, de um homem provém um homem, e do trigo provém trigo, mas não azeitona? Ou talvez seja produzido o osso quando os elementos se dispõem de uma determinada maneira? De fato, nada se gera pelo concurso fortuito dos elementos, como Empédocles declara, senão de acordo com 
uma determinada proporção. Qual é, então, a causa disto? Certamente não é o fogo ou a terra [...]. A causa é a ousía ${ }^{4}$ de cada coisa, e não somente a mescla e o intercâmbio do mesclado, como expressa Empédocles. Nestes casos, se aplica o nome de "casual" e não o de "proporção", já que é possível que as coisas se mesclem de modo fortuito (Gen. corr., 333b3-17).

No domínio em que absolutamente tudo tivesse sucedido por concomitância como se tivesse vindo a ser em vista de algo, as coisas ter-se-iam conservado na medida em que se teriam constituído de maneira apropriada por espontaneidade, mas teriam perecido e pereceriam todas as coisas que não teriam vindo a ser desse modo, como Empédocles menciona os bovinos de face humana (Ph. 198B27-31).

De acordo com o que a passagem da Geração e Corrupção sugere, e a passagem da Física indica, Empédocles sustentaria a tese segundo a qual, no domínio em que os entes naturais constituíam-se a partir de combinações aleatórias entre os elementos, os organismos que, casualmente, se ajustaram às exigências da vida mantiveramse preservados; já os que não se ajustaram, pereceram. Aristóteles encontra uma série de dificuldades nas implicações envolvidas nesta tese. Dificuldades estas, que suscitam alguns questionamentos concernentes ao processo de reprodução dos organismos: por que, na maioria das vezes, o indivíduo gerado se assemelha àquilo a partir do qual vem a ser gerado, isto é, como Aristóteles observa, por que, sempre ou no mais das vezes (hôs epì tò polý), do trigo provém trigo e não azeitona?

Ora, dado que a partir de uma combinação aleatória entre os elementos é possível o surgimento de uma variada gama de configurações composicionais, por que de um organismo qualquer advém, regularmente, outro do mesmo espécime? Ademais, uma vez que não há nenhum fator - interno ou externo ao processo de constituição - regulando os movimentos espontâneos dos elementos materiais, como explicar, então, a formação constante de determinados arranjos ou de estruturas adequados ao desempenho de certas funções orgânicas? E, visto que os seres vivos e as suas partes são o resultado de um simples agregado de elementos (Gen. corr. 334a27-31), como estes arranjos ou estruturas composicionais poderiam vir a apresentar, na compleição orgânica, propriedades que os componentes materiais, por si mesmos, seriam incapazes de adquirir?

Em conformidade com a concepção aristotélica, estas dificuldades concernentes a tese defendida por Empédocles, não teriam procedência, caso se

4. Neste contexto, o termo ousía parece se aproximar mais do sentido de "essência", mas alguns tradutores preferem traduzi-lo por "substância". Quando Aristóteles diz que "a causa é a ousía de cada coisa, e não somente a mescla e o intercâmbio do mesclado", ele está querendo dizer que a causa dos entes naturais não se reduz a uma simples mistura ao acaso dos elementos, nem ao intercâmbio pelos quais eles, espontaneamente, se interagem. Antes, a causa corresponde a certa proporção (lógos) que os elementos, por assim dizer, deixados a sua própria sorte, seriam incapazes de realizar. O que promove esta proporção é a forma do ente natural, pela qual o definimos, e que determina o que o ente é, ou seja, a sua essência (Metph. 1041b5 e ss.). 
considerasse um fator teleológico operando sobre o concurso fortuito dos elementos, que, por si mesmos, seriam incapazes de engendrar os arranjos composicionais que caracterizam os organismos. Um indivíduo gerado, no mais das vezes, assemelha-se aos seus progenitores - por exemplo, de homem provém um homem (Ph. 193b11-12), e não outro espécime -, porque a forma específica é transmitida à prole no ato da concepção, de modo a promover, sob determinações próprias a espécie, o desenvolvimento do novo organismo, consoante certo reordenamento das propriedades materiais. Assim, a forma, atuando como um fator teleológico, ao regular e determinar a reprodução dos seres vivos, explica porque, geralmente, de homem provém um homem, ou de trigo provém trigo.

Além do mais, a teleologia aristotélica sustenta que a configuração orgânica, ou a disposição composicional das partes, vem a ser ordenada em vista das funções ou operações vitais. Este ajuste ou adequação das partes às funções vitais depende, primariamente, de condições internas à constituição do animal, mas, com relação a algumas características específicas, depende, também, de condições externas. Em uma passagem de As Partes dos Animais, Aristóteles afirma o seguinte sobre a tromba do elefante:

O nariz do elefante é único, devido a seu tamanho e força extraordinários. É por meio de sua tromba, como se ela fosse uma mão, que o elefante leva a sua boca o alimento, tanto o sólido quanto o líquido. [...] A utiliza, de fato, exatamente como se fosse uma mão, porque o elefante é, por sua natureza, tanto um animal terrestre, como um habitante do pântano. Tem, pois, que obter seu alimento a partir da água; no entanto, tem que respirar (Part. An. 658b33-659a5). ${ }^{5}$

A função de (i) respirar ${ }^{6}$ e a função de (ii) se alimentar exige, como condição interna ou intrínseca a constituição do elefante (eléphas), a presença de partes

5. Com relação a esta passagem, Ackrill diz que Aristóteles se aproximaria do modo de falar do evolucionista: "se não encontrassem meios para respirar e alimentar-se nos pântanos, [sc. os elefantes] não teriam sobrevivido neles" (ACKRILL, 1981, p.48). Mas, de acordo com Bostock, seria a posição de Empédocles, e não a de Aristóteles, que se aproximaria mais das ideias evolucionistas, pois, como vimos, para Empédocles, os organismos que casualmente se ajustaram ou se adaptaram às exigências da vida sobreviveram; já os que não, pereceram (BOSTOCK, 2006, p. 50). No entanto, Charlton assinala que há inconsistências na comparação entre a concepção de Empédocles e a teoria darwinista: "Empédocles não pensa que a vida começa a partir de simples organismos, que foram, no entanto, tão bem adaptados para a sobrevivência de acordo com a sua simplicidade permitida: ele pensou que havia, antes, partes orgânicas separadas, como cabeças sem pescoço, totalmente incapazes de sobreviver (DK 31 A 72, B 57). [...] A proposta de Empédocles de que a divisão da espinha dorsal em vértebras é o resultado da fratura aleatória, por meio da flexão excessiva no útero (De part. an. I 640a21-2), parece ser tão absurda para Darwin, quanto para Aristóteles" (CHARLTON, 1992, p. 122).

6. Em Aristóteles, a respiração tem por função resfriar o organismo, na medida em que promove um equilíbrio do calor inato ou calor vital (Ver, por exemplo: Part. An. 668b32-669a7). O calor inato, proveniente, principalmente, do coração - ou da parte equivalente, no caso dos animais não sanguíneos (Juv. 469b7-13) -, não é algo que procede do fogo (Gen. An. 737a6-7), mas uma propriedade 
orgânicas tais como (i) pulmões, faringe, nariz etc., e (ii) estômago, esôfago, boca etc. Estas condições são fundamentais para que o elefante supra algumas de suas necessidades vitais. No entanto, o grande porte corporal do elefante relacionado às condições externas, ou seja, ao meio ambiente no qual vive, exigem que tal animal comporte uma particularidade estrutural, a saber, a tromba (proboskís).

A tromba do elefante apresenta-se tanto como o nariz, quanto o análogo à mão, na medida em que contribui para o processo respiratório e, também, é utilizada para conduzir o alimento até a boca. Por causa desta dupla atribuição funcional, a tromba caracteriza-se por ser larga e flexível. Conforme Aristóteles, há duas razões que explicam tal configuração: a tromba realiza a tarefa que, em outros animais, cumpre as patas dianteiras, isto é, apanhar o alimento, pois, por causa de seu peso e tamanho, as patas dianteiras só podem servir como suportes (Part. An. 659a24-29). Por viver em ambientes pantanosos, além de terrosos, e por ser lento, devido ao seu volume de grandes proporções, o elefante, ao passar uma boa parte do tempo em meio a águas relativamente profundas, faz uso de sua tromba, elevando-a a superfície, para respirar (Part. An. 659a9-14).

A partir deste exemplo, e do que se infere da concepção hilemórfica (de hilemorfismo: hýlè (matéria) + morphé (forma)) de Aristóteles, observa-se que, dada as condições internas e externas aos vários modos pelos quais os animais vêm a se constituir, a natureza enquanto princípio formal conduz teleologicamente a formação das partes orgânicas, de modo a adequá-las ao desempenho das funções ou atividades vitais. Sendo assim, seria possível explicar a constância com a qual se desenvolvem certos arranjos materiais, que compõe os organismos.

A formação das partes orgânicas ocorre na medida em que a natureza enquanto princípio formal organiza a composição material, de modo a promover certa proporção entre os elementos, atribuindo-lhes novas propriedades, com a finalidade de ajustá-los ao desempenho das atividades vitais. Os elementos, na composição (sýnthesis) orgânica, deixam de apresentar as suas propriedades essenciais para assumirem as propriedades requisitadas pelo ser vivo, não deixando, contudo, de preservarem em potência as propriedades que apresentavam em ato anteriormente à composição, voltando a manifestá-las novamente após a destruição do organismo (Gen. corr. 327b25-32; LEWIS, 1994, p. 273-274).

Distintamente da composição na qual se estabelece uma mera justaposição entre os elementos, originando agregados (soroí), Aristóteles chama de mistura (mîxis) quando os "ingredientes" envolvidos sofrem alterações (Gen. corr. 328b2122), de modo a gerar um todo distinto das partes que o constitui. Estas alterações acontecem no momento em que, na mistura, se estabelece certo grau de equilíbrio

anímica, a qual se poderia dizer que serve como um instrumento às funções da alma (psychế), tal como o movimento e a nutrição (Part. An. 652b7-13). 
entre os poderes (dynámeis) dos componentes, fazendo com que as diversas propriedades destes componentes se convertam em algo intermediário e comum (Gen. corr. 328a28-31). Assim, sob a intervenção da forma do ser vivo, a qual determina ordenadamente o conjunto das condições materiais necessárias a sua realização, vem a ser engendradas várias misturas, através das quais se formam as partes homogêneas (ex. ossos, carne, tendões), que, por sua vez, servem de substratos às partes não homogêneas (ex. rins, mãos, pulmões). Tendo em vista estas considerações, dissolve-se, portanto, a dificuldade de entender como os arranjos ou estruturas orgânicas manifestam determinadas propriedades que os elementos materiais, por si próprios, seriam incapazes de explicar.

Por fim, sobre a teleologia ou finalidade natural, cumpre observar que, às vezes, resulta algo falho dos processos que vem a ser em vista de algo. Para ilustrar este ponto, Aristóteles, no capítulo 8 do Livro II da Física, estabelece uma analogia entre técnica e natureza. Do mesmo modo que o erro pode ocorrer nas coisas que resultam da técnica, assim, também pode ocorrer nas coisas que resultam da natureza:

\footnotetext{
Visto que há coisas conforme à técnica nas quais o resultado correto se dá em vista de algo, ao passo que, nos produtos falhos, se tenta algo em vista de algo, mas não se acerta, é plausível que seja do mesmo modo também entre as coisas naturais, que os monstros sejam falhas de certo em vista de algo (Ph. 199b1-5).
}

Neste contexto, os exemplos que Aristóteles fornece a respeito dos erros que resultam da técnica são os seguintes: (i) "o escritor escreveu de modo incorreto" e (ii) "o médico incorretamente ministrou a droga" (Ph. 199a33-34). Ora, a fato de o escritor haver escrito de um modo incorreto, ou de o médico ter ministrado incorretamente uma droga, pressupõe uma meta a ser atingida, pois o incorreto só é identificado em referência àquilo que, supostamente, deveria ser realizado. Esperase do escritor uma boa grafia e do médico a cura pela droga ministrada, no entanto, aconteceu de o escritor e o médico não realizar adequadamente as suas respectivas tarefas.

Na natureza, acontece algo semelhante ${ }^{7}$. Dado que ocorrem falhas naturais, isto é, o surgimento de monstruosidades, segue-se que há na natureza, também, uma meta ou um acabamento (télos) a ser atingido, visto que é em relação a este

7. Embora haja semelhantes, há, também, diferenças: a técnica exige deliberação, mas a finalidade natural não (Ph. 199b26-8). Como Lucas Angioni diz: "Aristóteles afirma claramente que a deliberação não é condição necessária para a teleologia, e que seria absurdo pensar que fosse. O caráter teleológico da causalidade da natureza não implica nem exige atribuir a todos os entes naturais a capacidade de discernir um fim como bom e/ou a capacidade de determinar racionalmente os meios necessários a sua realização" (ANGIONI, 2009, p. 371). Em conformidade com estas considerações ver: BROADIE, 1990, p. 389-403. Para uma interpretação contrária, a qual sustenta que há certo antropomorfismo ou psicologização da natureza em Aristóteles ver: FURLEY, 1985, p. 177-82; SEDLEY, 1991. 179-96. 
acabamento que se considera ter havido falha no processo de geração orgânica. A partir do que se pode concluir da filosofia aristotélica, os monstros (tà térata), ou seja, as más-formações congênitas são originadas quando há, no ato da concepção, um enfraquecimento dos movimentos que procedem do sêmen masculino, prevalecendo a matéria proporcionada pela fêmea (Gen. An. 769b11-12). Deste modo, o princípio formal, que deveria conduzir a um adequado desenvolvimento dos arranjos materiais, falha na consecução do acabamento que lhe era devido. Em outros termos, a forma do vivente, isto é, aquilo que determina o que o ser vivo é, e pela qual o definimos, falha na consecução de sua plena, ou apropriada, realização.

\section{NECESSIDADE NATURAL}

De acordo com Aristóteles, há duas maneiras pelas quais a necessidade (anánkē) poderia operar entre as coisas naturais: ou, simplesmente, (i) "sem mais" (haplôs), isto é, de um modo absoluto, ou (ii) sob hipótese (ex hypothéseōs) (Ph. 199b3435). No primeiro caso, os entes naturais seriam constituídos única e exclusivamente por uma série de movimentos necessários provenientes da matéria elementar, da qual, consoante um processo espontâneo, os seres, em toda a sua complexidade, resultariam de uma combinação aleatória entre os elementos. Já no segundo caso, os entes naturais não seriam o resultado de uma combinação aleatória, mas os elementos se ordenariam, na composição, sob uma hipótese ${ }^{8}$, ou seja, conforme um princípio anterior, atuando teleologicamente.

Se, entre as coisas naturais, a natureza operasse segundo uma necessidade absoluta, como propõe os adversários de Aristóteles (principalmente Empédocles e Demócrito $^{9}$ ), então - supondo que os processos de constituição dos objetos da técnica fossem conduzidos de um mesmo modo que os processos de constituição dos entes naturais - é como se, por exemplo, a parede tivesse vindo a ser porque as coisas pesadas, como pedras, são, em virtude de suas propriedades essenciais, naturalmente levadas para baixo e as cosias mais leves, como terra e madeiras, são espontaneamente conduzidas para cima: a terra numa posição intermediária, e a madeira no topo, por ser mais leve que a terra (Ph. 199b35-200a5).

Porém, embora seja verdade que sem pedras, terra e madeiras, a parede não vem a ser (Ph. 200a5), estes itens são somente condições necessárias, mas não suficientes, para a efetiva produção da parede. As propriedades ou características

8. Como Angioni adverte, o termo "hipótese", neste contexto, "não preserva nenhum traço de acepção meramente epistemológica, ou seja, 'hipótese' não designa uma mera conjectura, uma suposição transitória, assumida para fins de averiguação posterior. 'Hipótese' quer dizer, neste contexto, fundamento anterior" (ANGIONI, 2002, p. 110-111).

9. Com relação a Empédocles, ver por exemplo: Gen. corr. 333b3-17, Part. An. 640a19-22; no que diz respeito a Demócrito, ver: Gen. An. 789b3-4. 
essenciais próprios dos componentes materiais devem ser incorporadas por um princípio anterior, estipulado como hipótese, para que as devidas disposições composicionais, que constituem a parede, sejam efetivamente estabelecidas. No entanto, estas propriedades são indispensáveis à realização do produto, na medida em que se apresentam como suporte material, sem o qual a parede não poderia ser produzida, se bem que não explicam por que aquilo do qual resultam vem a adquirir, enquanto tal, outras propriedades. O que explica as características essenciais da parede são as suas funções, a saber, as funções de esconder, proteger, conservar determinados objetos, e não uma soma das propriedades da pedra, da terra e da madeira.

Da mesma forma, o princípio material do ser humano, a saber, o kataménia (resíduo menstrual), proveniente da fêmea, apresenta-se como condição necessária para que haja a geração de um novo indivíduo, visto que é a partir deste material que o corpo vem a se constituir (Gen. An., I.20, 729a9-11). Contudo, o kataménia, por si só, não é condição suficiente para a formação das partes do organismo (Gen. An. 730a29-30), e suas propriedades essenciais não são capazes de explicar por que o organismo apresenta características anímicas, mesmo sendo uma mistura (mîxis) de elementos ${ }^{10}$, a partir da qual o ser vivo vem a ser constituído. Antes, é em função de um princípio anterior (a forma do homem), assumido como hipótese, o qual atua, no ato da fecundação, através dos movimentos imprimidos ao kataménia pelo sêmen procedente do macho, isto é, o esperma (Gen. An. 716a5-8) ${ }^{11}$, que vem a ser

10. É importante ressaltar que os elementos, ainda que numa mistura, preservam suas propriedades disposicionais, pois estas disposições serão, posteriormente, responsáveis pela deterioração do organismo. Como Whiting escreve: "Aristóteles argumenta em GC I.10 que os elementos em uma mistura não podem subsistirem sem serem alterados (pois, neste caso, seria um mero agregado e não uma mistura), nem serem destruídos. Os elementos são atualmente um novo composto, mas, potencialmente, o que eles foram anteriormente à mistura; suas potencialidades (dýnamis) são preservadas". E, acrescenta: “Os organismos vivos envelhecem e decaem, por que os elementos que os constituem tendem a se moverem para os seus lugares naturais - fogo para o alto e terra pra baixo - com o resultado que os elementos, gradualmente, vêm a se separarem uns dos outros, e deixam de estarem presentes nas proporções necessárias à existência das partes homogêneas" (WHITING, 1992, p. 82-3).

11. O esperma, segundo Aristóteles, é "um resíduo do alimento útil em seu último estágio" (Gen. An., I.18, 726a27). Com esta afirmação, o que o filósofo pretende dizer é que o sangue, sendo a forma final do alimento para os animais sanguíneos, e para os não sanguíneos o análogo, ao sofrer um processo de cocção devido ao calor corporal, é convertido em esperma. O sangue, uma vez distribuído de um determinado modo no organismo, produz as partes do animal, mediante a ação do calor vital, sob as rédeas da psyché. No macho, o que sobra deste processo vem a ser transformado em sêmen. Por outro lado, na fêmea, pela debilidade inerente a sua própria natureza, não há calor suficiente para que o sangue seja convertido em sêmen. Assim, as fêmeas, ao invés de esperma, produzem uma secreção sanguínea, a qual corresponde ao resíduo menstrual, isto é, o kataménia. O resíduo menstrual seria, então, como Aristóteles declara, um esperma impuro, necessitado de elaboração, de modo que o embrião é uma decorrência da união ou mescla entre o esperma impuro (resíduo menstrual) e o sêmen (esperma puro) (Gen. An. 726b2-11; 726b32-727a2; 728a19-22; 728a27-28; 728b34-35). Conforme Ester Sánchez, a "teoria de que o sangue da menstruação era a matéria da qual se formava o embrião, foi aceita sem questionamento durante toda a Antiguidade e até o século XVII, quando William 
desencadeado o processo de desenvolvimento das partes orgânicas; sendo as funções inter-relacionadas destas partes que explicam por que o organismo, enquanto tal, exibe as propriedades que o distingue.

As funções, portanto, desempenham um papel de destaque nas explicações relativas à formação dos organismos ${ }^{12}$. É em vista delas que se delimita a necessidade de certas propriedades composicionais, sem as quais não haveria constituição orgânica. A partir das funções vitais, os movimentos absolutamente necessários da matéria elementar, na composição do ser vivo, tornam-se necessários sob hipótese, pois se convertem em condições imprescindíveis à realização daquilo que foi determinado pelo fundamento anterior (hipótese). Assim, no processo de constituição dos entes naturais, a necessidade sob hipótese, através de um princípio anterior, subordina a necessidade absoluta da matéria, de modo que este tipo de necessidade passa a estar envolvida no primeiro tipo.

Para ilustrar esta relação de subordinação da necessidade absoluta pela necessidade sob hipótese, vejamos o exemplo do serrote, que Aristóteles formula no capítulo 9 do Livro II da Física:

Por que o serrote é de tal e tal tipo? Para isso e em vista disso. No entanto, é impossível que isso (o em vista de quê) venha a ser, se não for de ferro; portanto, é necessário que seja de ferro, se há de ser serrote e se há de se dar a função dele. Pois bem: aquilo que é necessário se dá sob hipótese, mas não como acabamento, pois é na matéria que está aquilo que é necessário, e o em vista de quê está na definição (Ph. 200a10-15).

O serrote, para cumprir a função que o define, é necessário que apresente certa configuração, ou seja, possuir dentes capazes de serrar, e ser composto por

Harvey a refutou em sua obra Exercitationes de generatione animalium (1651). Através de seus estudos sobre a reprodução e do desenvolvimento dos cervos, descobriu que todo animal provém de um ovo. Antes do século findar, postulou-se a hipótese de que os ovários femininos eram a fonte destes ovos, e que o esperma forneceria o material hereditário do macho" (SÁNCHEZ, 1994, p.109, n. 164). 12. Como Angioni explica, "em alguns contextos, 'érgon' pode ser traduzido por 'obra', 'proeza' etc., mas, no contexto da filosofia da natureza, 'érgon' tem o sentido de atividade ou operação própria, que não apenas cabe essencialmente a certa coisa, mas também a define. [...] Uma coisa qualquer é precisamente o que ela é tão somente se desempenhar as funções que essencialmente lhe são atribuídas. Se algo ainda preservar outras propriedades que lhe cabem essencialmente, mas não for capaz de executar a função, não mais será denominado do modo como costumamos denominá-lo, 'a não ser homonimamente'”' (ANGIONI, 2009, p. 381-2). Com efeito, em De Anima, Aristóteles diz o seguinte: "Se olho fosse um animal, a alma dele seria a vista: pois é esta a essência do olho segundo a definição; e o olho é a matéria da vista, e se esta última estiver faltando, não mais há olho, a não ser homonimamente, tal como o de pedra e o desenhado" (De An. 412b18-21). Em outras palavras, se o olho não for mais capaz de desempenhar sua função orgânica, a saber, proporcionar a visão, então não mais será, propriamente, um olho, pois é justamente pela função de ver que o olho vem a ser o que é, e pela qual o definimos enquanto tal. Neste sentido, Shields afirma que, em Aristóteles, "algo pertence a um tipo $F$ apenas se puder realizar a função definitiva desse tipo". Por exemplo, "qualquer coisa que - e somente o que - tem a capacidade de ver será um olho" (SHIELDS, 1993, p. 168). 
um material cujas propriedades são apropriadas ao desempenho de sua tarefa, tal como o ferro, por ser suficientemente consistente, resistente, pesado etc.; mas, não um material como, por exemplo, madeira ou lã (Metph. 1044a27-30). Sendo assim, poder-se-ia supor que é pelo simples fato de ter tal configuração e composição que o serrote é capaz de serrar. Porém, apesar de haver implicação recíproca entre a função e algumas propriedades do material adequado, cabe a função, assumida como princípio preponderante, e não aos atributos materiais, a primazia explanatória, pois é ela que explica por que se determina a configuração (skhêma) e se delimita as propriedades composicionais necessárias a sua realização.

É possível aferir o raciocínio contido na passagem sobre o serrote aos processos implicados na constituição dos organismos vivos. A necessidade absoluta, proveniente das propriedades essenciais dos elementos materiais, na composição do ser vivo, se dá sob hipótese, mas não como acabamento, pelo qual nada precisasse ser aditado. As propriedades da matéria são apropriadas pelo organismo, adequandoas em vista de um acabamento, na medida em que são subordinadas por um fator teleológico admitido como princípio anterior, ou seja, como hipótese. Deste modo, as propriedades dos componentes materiais, e os movimentos absolutamente necessários das quais decorrem, no organismo vivo, encontram-se, também, sob hipótese, uma vez que são requisitados para a efetividade da função ou funções que caracterizam os seres vivos (ANGIONI, 2009, p. 385-386).

Por exemplo, os dentes (odoús), para serem capazes de cumprir a função orgânica que os definem, a qual, em alguns animais corresponde ao ato de elaborar o alimento, e, em outros, além disso, para a luta (Part. An.655b8-11), devem apresentar certas propriedades tais como dureza e solidez. Para tanto, é necessário que os dentes comportem uma natureza terrosa (geódēs) (Part. An. 655b12-14). Sendo assim, a necessidade absoluta decorrente do material terroso dos dentes, na compleição orgânica, se dá, também, sob hipótese, pois as propriedades deste material (dureza, solidez etc.) são condições necessárias a fim de que haja a efetividade de certa função ou funções desempenhadas pelo animal; embora não sejam, por si próprias, condições suficientes, porque elas vêm a ser, antes, incorporadas e subordinas às exigências da vida pela forma do ser vivo, a qual é transmitida de geração a geração através do processo de reprodução.

De acordo com as considerações precedentes, percebe-se que, por um lado, a matéria está associada à necessidade absoluta, e, por outro, a forma está associada à necessidade hipotética da teleologia. Assim, em consonância com a concepção hilemórfica, cabe ao investigador da natureza levar em conta os dois tipos de causalidade (Part. An. 642a13-14), cada qual correspondendo aos dois modos de necessidade. Mas, como já fora indicado, a primazia explanatória deve ser concedida a causalidade representada pela necessidade hipotética, uma vez que 
este tipo de causalidade envolve aquele relacionado à necessidade absoluta, a saber, a causalidade proveniente dos elementos materiais, na medida em que fornecem o substrato a partir do qual o organismo se constitui, e na medida em que contribuem para a realização das funções orgânicas.

Por um lado, a forma, vinculada à necessidade hipotética da teleologia, explica por que os entes naturais, definidos por certas funções, possuem tais e tais propriedades, e porque apresentam determinados arranjos composicionais. Por outro, a matéria, relacionada à necessidade absoluta, explica não o porquê de o ente natural ter tais e tais propriedades, mas, simplesmente, quais são estas propriedades e os movimentos necessários dela decorrentes. Contudo, estes movimentos não são capazes de explicar, por si próprios, a razão pela qual os entes naturais devem comportar certas características que lhes são apropriadas. É a forma-função o fator responsável pelo devido encadeamento dos movimentos necessários da matéria, de modo a conduzi-los em vista de um acabamento.

Embora a forma deva ser considerada o princípio preponderante na investigação natural, a definição dos seres deve incluir, também, a matéria, na exata medida em que esta apresenta as propriedades requisitadas para a função. Para exemplificar esta tese, Aristóteles recorre novamente ao exemplo do serrote, no capítulo 9 do Livro II da Física:

Para quem definiu que a função de serrar é uma divisão de tal e tal tipo, esta, precisamente, não poderá ser o caso, se não dispuser de dentes de tal e tal tipo; estes, por sua vez, não poderão ser o caso, se não forem de ferro. De fato, também na definição há algumas partes como matéria da definição (Ph. 200b5-9).

De uma maneira primordial, a definição do serrote coaduna-se com o esquema da necessidade hipotética da teleologia: o serrote é definido por sua função, isto é, ser capaz de serrar. Dada esta definição, deduz-se que, para ser capaz de serrar, o serrote deve ter algumas propriedades indispensáveis, tal como dentes afiados dispostos de tal e tal modo. Desta consequência, segue-se outra, a saber, estes dentes devem ser feitos de um material apropriado: ferro ou bronze ${ }^{13}$, pelo fato de serem relativamente duros, resistentes, pesados etc. Entre estas propriedades requisitadas pela função do serrote e o ferro, ou o bronze, se estabelece uma relação de necessidade absoluta, a qual prescinde da hipótese de haver serrotes. $\mathrm{O}$ ferro ou o bronze, independentemente de constituir um serrote ou um machado, possui, em si mesmos, as propriedades compatíveis à função de serrar. A necessidade absoluta proveniente destas propriedades do ferro ou do bronze é, então, assimilada pela

13. Da mesma forma que o machado, o serrote deve ser constituído por um material duro para cumprir a sua função, tal como ferro ou bronze (Part. An. 642a9-11). A diferença é que o machado terá certa configuração (skhêma), e o serrote outra. 
forma-função, enquanto princípio causal, tornando-se, também, necessidade sob hipótese (ANGIONI, 2009, p 378).

Para estabelecer um paralelo entre o exemplo do serrote, relativo à técnica, e um exemplo referente a algo natural, consideremos, mais uma vez, o caso dos dentes dos animais. Os dentes são definidos pela função de elaborar o alimento e/ou servir de instrumento de ataque ou defesa. A partir desta definição, conclui-se que, para que o animal possa elaborar o alimento, os dentes molares devem ser largos e úteis para aplainar o alimento, e, no caso dos carnívoros, os caninos devem ser agudos, adaptados para dividir (Ph. 198b24-26; Part. An. 661a34 e ss.). Disto, resulta que os dentes precisam ser constituídos por um material adequado, de natureza terrosa, pois devem comportar alguns atributos como, por exemplo, certa dureza e solidez. No entanto, entre estes atributos e o elemento terra, o qual, obviamente, predomina no material terroso, há uma relação de necessidade absoluta, que não depende da hipótese de haver dentes. São próprias ao elemento terra, independentemente da composição orgânica, as características materiais requisitadas pelas funções desempenhadas pelos dentes. Deste modo, a necessidade absoluta que decorre das propriedades essenciais do elemento terra é absorvida pela forma do animal, vindo a ser, também, no organismo, necessidade sob hipótese.

\section{CONSIDERACOÕES FINAIS}

A investigação natural, portanto, consoante o modelo hilemórfico, envolve tanto o princípio formal, quanto o princípio material. Por conseguinte, uma definição mais completa deve mencionar não apenas a forma-função, mas, também, o suporte material a partir do qual é possível a realização da função ou o conjunto de funções, que caracterizam os entes naturais, por exemplo: os dentes são definidos por certo material terroso, disposto de tais e tais modos, capaz de elaborar o alimento e/ou servir de instrumento de ataque ou defesa. Contudo, a matéria mencionada na definição não é aquela que existe aquém e além da composição, ou seja, a matéria subjacente, a qual, no caso dos dentes dos animais, corresponde principalmente ao elemento terra, mas sim a matéria apropriada. A matéria apropriada (Metph. 1044b24, 1049a19-21), relativamente ao animal, diz respeito não aos elementos (terra, água, ar, fogo) considerados em si mesmos, mas a uma mistura desses elementos, na qual eles adquirem as propriedades relevantes que habilitam os organismos ao efetivo desempenho da função que lhes é própria. Por exemplo: a matéria apropriada do dente é certa mistura terrosa, disposta de tais e tais modos, na qual prevalecem determinadas características do elemento terra, tais como dureza e solidez.

Porém, visto que, como vimos, os atributos do elemento terra são aproveitados pela forma-função do animal, enquanto princípio e hipótese, por 
que, então, a matéria subjacente, e os movimentos absolutamente necessários a ela correlacionados, não devem figurar na definição dos entes naturais? Estes itens não devem constar na definição porque a justa proporção de elementos e as propriedades que dela resultam só podem ser explicadas pela forma, assumida como fator teleológico, de modo que o devido encadeamento das sequências de movimentos necessários da matéria, não fica a cargo da espontaneidade dos elementos, mas da causalidade formal-final.

Ademais, a causalidade formal-final promove a emergência de certas propriedades que os elementos, por meio da simples interação espontânea de seus movimentos, não poderiam contrair. Por exemplo, o sangue, na composição orgânica, tem a propriedade de ser quente e líquido, mas, ao separar-se, tornase frio e sólido (Part. An. 649b28-31). O sangue é quente e líquido, na medida em que vem a ser elaborado por um processo de cocção (pépsis), a fim de poder desempenhar a função que lhe corresponde, a saber, servir de alimento as partes do animal (Part. An. 650a34-35). Assim, a forma do animal insere certas propriedades ao material sanguíneo, as quais, sendo essenciais ao organismo, são acidentais para os elementos que a compõe. De acordo com Aristóteles, a forma, associada à necessidade hipotética da teleologia, ao determinar os entes naturais, administra os movimentos próprios da matéria, associada à necessidade absoluta. É, justamente, em razão desta correlação entre matéria e forma que a natureza será caracterizada por um impulso intrínseco à mudança (Ph. 192b20-23).

\section{REFERÊNCIAS}

Obras de Aristóteles:

ARISTÓTELES. Aristotelis Opera. BEKKER, I. (ed.). Academia Regia Borussica, Vols. I-II, Berlim, 1831.

. The Metaphysics, Books I-IX. Trad. London: The Loeb Classical Library, 1947.

. Generation of Animals. Trad. A. L. Peck. London: The Loeb Classical Library, 1953.

. On Sophistical Refutations; On Coming-to-be and Passing Away; On the Cosmos. Trad. E. S. Foster and D. J. Furley. London: The Loeb Classical Library, 1955.

. On the Soul; Parva Naturalia, On Breath. Trad. W. S. Hett. London: The Loeb Classical Library, 1957. 
. Parts of Animals; Movement of Animals; Progression of Animals. Trad. A. L. Peck. London: The Loeb Classical Library, 1961.

. Reproduccíon de los Animales. Trad. y notas de E. Sánchez. Madri: Biblioteca Clásica Gredos, 1994.

. As Partes dos Animais, Livro I. Trad. e comentários de L. Angioni. Campinas: Cadernos de História e Filosofia da Ciência, vol. 9, série 3, n. especial, 1999.

. Acerca de la Generación y la Corrupción; Tratados Breves de Historia Natural. Trad. y notas de E. La Croce, e A. B. Pajares. Madri: Biblioteca Clásica Gredos, 1998.

. Partes de los Animales; Marcha de los Animales; Movimiento de los Animales. Trad. y notas de E. J. Sánchez-Escariche, e A. A. Miguel. Madri: Biblioteca Clásica Gredos, 2000.

2002.

Física. Trad. y notas de G. R. de Echandía. Madri: Biblioteca Clásica Gredos,

Acerca del Alma. Trad. y notas de T. C. Martínez. Madri: Biblioteca Clásica Gredos, 2003.

_. Metafísica. Trad. y notas de T. C. Martínez. Madri: Biblioteca Clásica Gredos, 2006.

. Física I-II. Trad. e comentários de L. Angioni. Campinas: Ed. Unicamp, 2009.

Bibliografia Secundária:

ANGIONI, Lucas. Física I - II. Trad. e notas de L. Angioni. Clássicos da Filosofia: Cadernos de Tradução n. 1, IFCH/UNICAMP, 2002.

Física I-II. Trad. e comentários de L. Angioni. Campinas: Ed. Unicamp, 2009.

ACKRILL, J. L. Aristotle the Philosopher. Oxford: Clarendon Press, 1981.

BOSTOCK, David. Space, Time, Matter and Form: Essays on Aristotle's Physics. Oxford: Oxford University Press, 2006.

BROADIE, Sarah Waterloo. Nature and Craft in Aristotelian teleology. In: D. Devereux et

P. Pellegrin (eds.), Biology, Logique et Métaphysique chez Aristote. Paris: Éditions du CNRS, 1990, p. 389-403. 
CHARLTON, William. Aristotle's Physics - Books I and II. Translated with introduction and notes by W. Charlton. Oxford: Clarendon Press 2a Ed. (Clarendon Aristotle Series), 1992.

FURLEY, David. The Rainfall Example in Physics II 8. In: A. Gotthelf (ed.), Aristotle on Nature an Living Things. Pittsburgh, Brsitol: Mathesis publications, 1985, p. 17782.

KIRK, G. S.; RAVEN, J. E. \& SCHOFIELD, M. The Presocratic Philosophers. Cambridge, Cambridge University Press, 1984.

LEWIS, Frank A. Aristotle on the Relation between a Thing and its Matter. In: T. Scaltsas, D. Charles e M. L. Gill (eds.), Unity, Identity and Explanation in Aristotle's Metaphysics. Oxford: Clarendon Press, 1994, p. 247-277.

SÁNCHES, Ester. Reproduccíon de los Animales. Trad. y notas de E. Sánchez. Madri, Biblioteca Clásica Gredos, 1994.

SEDLEY, David. Is Aristotle's teleology anthropocentric?. Phronesis 36, 1991, 179-96.

SHIELDS, Christopher. Some Recent Approaches to Aristotle's De Anima. In: D. Hamlyn, Aristotle De Anima (Books II - III). Oxford: Clarendon Press, 1993, p. 157-81.

WHITING, Jennifer E. Living Bodies. In: M. Nussbaum e A. Rorty (eds.), Essays on Aristotle's De Anima. Oxford: Clarendon Press, 1992, p. 75-91. 